\title{
The Relationship between Frequency Dependence of Action Potential Duration and the Expression of TRPC3 in Rabbit Ventricular Myocardium
}

\author{
Yong Wang ${ }^{a}$ Mo-Si Chen ${ }^{a}$ Hong-Chang Liu ${ }^{a}$ Jun-Hua Xiao ${ }^{a, b}$ Jia-Ling Wang, \\ aDepartment of Pharmacology, Tongji Medical College, Huazhong University of Science and

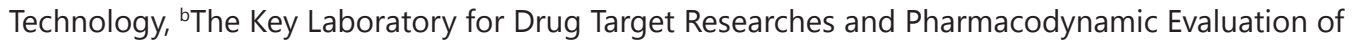 \\ Hubei Province, Wuhan, PR China
}

\section{Key Words}

Frequency dependence - Action potential duration - Transient receptor potential canonical channel $3 \cdot$ Ventricular myocardium

\begin{abstract}
Background/Aims: Cardiac action potential duration (APD) is regulated by heart rate, leading to the trans-membrane movement of inorganic ions. Whether the alteration of heart rate can affect the expression of transient receptor potential canonical channels (TRPCs), further studies should be made. We investigated the changes of APD at different stimulus frequencies and their influences on the expression of TRPCs in rabbit ventricular myocardium. Methods: Monophasic action potential (MAP) was recorded by contact electrode technique in different programmed stimulus frequencies on rabbit ventricular epicardium in vivo, and the expression of TRPCs was detected using RT-PCR and Western blot. Results: At the frequency range of 4.5$7.5 \mathrm{~Hz}$, APD gradually shortened with the increase of stimulus frequency, showing the property of significant frequency dependence in rabbit ventricular myocardium in vivo. Compared with 4.5 Hz group, TRPC3 mRNA and protein expression increased in $6 \mathrm{~Hz}$ and $7.5 \mathrm{~Hz}$ groups by way of frequency dependence. Both amiodarone (AM) and neferine (Nef) could prolongate APD and showed characters of frequency independence at the designed frequency. In contrast with $4.5 \mathrm{~Hz}$ control group, it was Nef treatment group rather than AM treatment group that could obviously increase the expression of TRPC3 mRNA and protein. Conclusions: At the frequency range of 4.5-7.5 Hz, frequency-dependent shortening of APD was associated with the expression of TRPC3. AM and Nef exhibited frequency-independent lengthening of the APD. Nef may prolong APD via the increasement of TRPC3.
\end{abstract}


Wang et al.: Relationship between Frequency Dependence of APD and TRPC3

\section{Introduction}

The cardiac action potential is composed of various ion channel currents, and the action potential duration (APD) is frequency-dependent characteristic in some mammal species including human, namely faster stimulation rates lead to a physiological shortening of APD [1]. A number of mechanisms may contribute to this phenomenon. These include incomplete deactivation of the slow component of the delayed rectifier potassium current (IKs) during the short diastolic periods [2,3], an increase in outward current or a decrease in inward current across the $\mathrm{Na}^{+} / \mathrm{Ca}^{2+}$ exchanger(NCX) [4, 5], an increase in the inward rectifier repolarizing potassium current (IK1) [6], a decrease in the inward calcium current [7], and the relation between potassium and calcium current [6]. The length of APD in isolated myocytes is determined by the balance of outward and inward current.

Transient receptor potential (TRP) channels are a superfamily of non-selective cation channels that sharing the common features of six transmembrane segments and can be activated or regulated by a wide variety of stimuli. The transient receptor potential canonical channels (TRPCs) are a subfamily of TRP channels, including seven members of the family TRPC1-7, and have been demonstrated to play a variety of roles in cellular calcium homeostasis. Activation of the TRPCs permits $\mathrm{Ca}^{2+}$ and $\mathrm{Na}^{+}$entry into the cell and the permeability to cations depends on the different TRPCs family members [8-10].

A recent article reported that TRPCs can form a macromolecular complex with the Ca1.2 $\alpha 1 \mathrm{C}$ subunit of the L-type $\mathrm{Ca}^{2+}$ channel. It has been indicated that the voltage-independent TRPCs may participate in the functioning of L-type voltage-gated calcium channel in the embryonic chick heart [11]. Both TRPC1 and TRPC6 are potential candidates for stretchactivated non-selective cation channels $\left(\mathrm{SAC}_{\mathrm{NSC}}\right)$, and the nonspecific ion current which they carried maybe change the action potential configuration potentially [12,13]. Stretch through increasing ventricular load can mediate a decrease in ventricular APD [14]. These suggest that non-selective cation channels or voltage-independent currents may also affect action potential formation and participate in the frequency dependence of APD.

Many antiarrhythmic agents that lengthen APD (such as quinidine, dofetilide) may exhibit reverse rate dependence, ie, the effect of a drug to prolong APD may be greater at slow heart rates, but the magnitude of the prolongation declines as heart rate increase [15]. As a result of reverse use dependence, these drugs have the least effect during tachycardia and enhance their proarrhythmic potential at normal or slow rates, which limited their development and clinical application [16].

Neferine (Nef) is one of the three main bisbenzylisoquinoline alkaloids, which are derived from a traditional Chinese medicine herb, such as Nelumbo nucifera Gaertner's seeds. Previous experimental studies had demonstrated that Nef has the effects of antiarrhythmia and depression of myocardial contractility, its mechanisms may be associated with nonspecific inhibition of the currents of $\mathrm{Ca}^{2+}, \mathrm{Na}^{+}$and $\mathrm{K}^{+}[17,18]$.

The aims of the present study were to elucidate: (1) the relationship between frequency dependence of APD and the expression of TRPCs in rabbit myocardium; (2) the roles of TRPCs in the process of APD frequency dependence and (3) whether TRPCs are involved in the drug effects of APD prolonging.

\section{Materials and Methods}

\section{Materials}

Amiodarone (AM) hydrochloride was obtained from Sanofi-Aventis (France) and dissolved in $0.9 \%$ saline. Nef (FW=625, purity $\geq 98 \%$ by HPLC) was extracted from the seed embryo of Nelumbo nucifera Gaertn by the Phytochemistry Laboratory of the Department of Pharmacology, Tongji Medical College of Huazhong University of Science and Technology. Anti-TRPC1, Anti-TRPC3, Anti-TRPC6 antibodies were purchased from Alomone Labs Ltd. 
Wang et al.: Relationship between Frequency Dependence of APD and TRPC3

\section{Experimental animals}

Male or female New Zealand white rabbits weighing 1.8-2.4 kg were used in this study. Rabbits were housed under standard conditions (room temperature $20-28^{\circ} \mathrm{C}$ ) with a $12 \mathrm{~h}$ light/dark cycle, feeding standard laboratory chow and water ad libitum. All rabbits were treated in accordance with the Guide for Care and Use of Laboratory Animals, and all experimental procedures were approved by the Ethics Committee of Laboratory Animals of Tongji Medical College of Huazhong University of Science and Technology.

\section{MAP recordings in vivo}

Rabbits were anesthetized with $20 \%$ urethane $5 \mathrm{ml} / \mathrm{kg}$ followed by an intravenous infusion via the lateral ear vein, and then were intubated and ventilated with an animal respirator (DHX-150B, Chengdu instrument factory, China), maintaining common tidal volume and breathing rate. After a left thoracotomy, the heart was suspended in a pericardial cradle. The epicardium was kept moist with warm Tyrode solution. Monophasic action potential (MAP) was recorded using a custom-made contact probe, which was positioned on the left ventricle epicardium. In brief, the MAP recording probe consisted of a L-shaped cantilever with an $\mathrm{Ag}-\mathrm{AgCl}$ electrode mounted on its distal end. The exploring electrode at the tip of the probe was $1 \mathrm{~mm}$ in diameter and embedded in an insulated epoxy resin, the distal tip of which was $1 \mathrm{~mm}$ long and naked. Continuous contact of the tip electrode with the epicardial surface of the beating heart was provided by a spring-loaded mechanism. The reference electrode was fixed to the subcutaneous tissue of chest. The MAP signals were amplified and recorded with biological signal collecting and processing system (RM-6240 system, Chengdu instrument factory, China). A pair of stimulation electrodes made of teflon-coated stainless steel wire were inserted in the atrial appendage of the right atrium. The heart was driven by basic electrical stimuli of 1.5 folds threshold strength and 2 ms duration. Pacing protocols were generated using a custombuilt programmable stimulator provided by RM-6240 system.

\section{Experimental protocols}

Pacing was started at the basic driven frequency (usually $4.5 \mathrm{~Hz}$ ) able to overdrive the spontaneous heart rate through a pair of needle electrodes placed in the right atrium. Stimulation protocol was maintained constant for $2 \mathrm{~min}$ at each frequency until a steady state was reached, and then intrinsic heart rate was resumed for $3 \mathrm{~min}$. Measurements of APD were obtained at the frequency range of 4.5-7.5 Hz, starting with the basic driven frequency to overdrive the spontaneous rhythm and continuing in incremental steps of 0.5 $\mathrm{Hz}$ until action potential refractory period was appeared.

Obtained measurements in the drug-free state, the uniform protocol was repeated from the same epicardial site after lateral ear vein injection of either $5 \mathrm{mg} / \mathrm{kg}$ AM or $2.5 \mathrm{mg} / \mathrm{kg} \mathrm{Nef}$.

APD at $90 \%$ of depolarization (APD90) was determined automatically by a data processing software built in biological signal collecting and processing system (RM-6240 system, Chengdu instrument factory, China) with a maximum sampling rate of $40 \mathrm{kHz}$.

Frequency dependence of APD on TRPCs expression of rabbit ventricular myocardium

The rabbit were randomized into four groups as follows: 1) sinus rhythm group, 2) $4.5 \mathrm{~Hz}$ group, 3 ) 6 Hz group, 4) $7.5 \mathrm{~Hz}$ group. Pacing at the stimulus frequency of $4.5 \mathrm{~Hz}, 6 \mathrm{~Hz}$, and $7.5 \mathrm{~Hz}$ for $10 \mathrm{~min}$, the hearts were taken out and then the expressions of TRPCs were detected using RT-PCR or Western blot.

\section{Effect of Nef or AM on TRPCs expression}

The rabbit were randomized into three groups as follows: 1) sham group, 2) AM group, 3) Nef group. Given intravenous injection of $5 \mathrm{mg} / \mathrm{kg} \mathrm{AM}$ or $2.5 \mathrm{mg} / \mathrm{kg}$ Nef in rabbits, a continuous $4.5 \mathrm{~Hz}$ electrical stimulation of 10 min was applied on rabbit myocardium after administration. Then the hearts were taken out rapidly and the expressions of TRPCs were detected.

Reverse transcription-polymerase chain reaction (RT-PCR) for TRPCs $m$ RNA expression analysis

Total RNA was extracted from each left ventricular tissue using a Trizol reagent kit (Invitrogen Inc.) according to the manufacturer's instruction. Quantification and purity of RNA were confirmed by the ratio of OD260 to OD280 determined by an Ultraviolet/Visible spectrophotometer (752 UV/VIS, Shanghai Sunny Hengping Scientific Instrument Co., Ltd, China); RNA samples with the OD260 to OD280 ratio between 1.8 and 2.0 were used for RT-PCR. The first-strand complementary DNA (cDNA) was synthesized from the total 
Wang et al.: Relationship between Frequency Dependence of APD and TRPC3

Table 1. Experimental primers of corresponding genes for RT-PCR

\begin{tabular}{|c|c|c|c|c|}
\hline $\begin{array}{l}\text { Gene } \\
\text { (Rabbit) }\end{array}$ & & Length (bp) & $\operatorname{Tm}\left({ }^{\circ} \mathrm{C}\right)$ & Cycles \\
\hline TRPC1 & $\begin{array}{l}\text { Forward: 5'-CACTCATTCATCGGCACTTG-3' } \\
\text { Reverse: 5'-GCTCGAGCAAACTTCCATTC-3' }\end{array}$ & 242 & $\begin{array}{l}57.2 \\
57.5\end{array}$ & 25 \\
\hline TRPC2 & $\begin{array}{l}\text { Forward: 5'-CCTCATCTTCCTGCTTGGAG-3' } \\
\text { Reverse: 5'-TCCAGGAAGTTCCACCAGTC-3' }\end{array}$ & 189 & $\begin{array}{l}57.7 \\
58.9\end{array}$ & 30 \\
\hline TRPC3 & $\begin{array}{l}\text { Forward: 5'-TTGTGCTGGTTGTAGCCTTG-3' } \\
\text { Reverse: 5'-GGTGATGCCTTCAAACCTGT-3' }\end{array}$ & 182 & $\begin{array}{l}58.7 \\
58.4\end{array}$ & 25 \\
\hline TRPC4 & $\begin{array}{l}\text { Forward: 5'-CTCTGGGAAGAATGCTCCTG-3' } \\
\text { Reverse: 5'-ATGCTGGGCTTTAACATTGG-3' }\end{array}$ & 248 & $\begin{array}{l}57.8 \\
56.7\end{array}$ & 30 \\
\hline TRPC5 & $\begin{array}{l}\text { Forward: 5'-TGGAATCGTTCAGCAGCACT-3' } \\
\text { Reverse: 5'-AGCAAGTCACAAGCCTCTCC-3' }\end{array}$ & 264 & $\begin{array}{l}60 \\
60\end{array}$ & 30 \\
\hline TRPC6 & $\begin{array}{l}\text { Forward: 5'-ACATGGGTCAGAATGCCCTG-3' } \\
\text { Reverse: 5'-GGTTGCTAACCTCCTGCCTT-3' }\end{array}$ & 191 & $\begin{array}{l}60 \\
60\end{array}$ & 30 \\
\hline TRPC7 & $\begin{array}{l}\text { Forward: 5'-TAGCGAAGACCCTGTCCTCA-3' } \\
\text { Reverse: 5'-GCACACCCACCACAAAATCC-3' }\end{array}$ & 131 & $\begin{array}{l}60 \\
60\end{array}$ & 25 \\
\hline$\beta$-actin & $\begin{array}{l}\text { Forward: 5'-AGTGCGACGTGGACATCCG-3' } \\
\text { Reverse: 5'-TGGCTCTAACAGTCCGCCTAG-3' }\end{array}$ & 295 & $\begin{array}{l}62.6 \\
61.2\end{array}$ & 30 \\
\hline
\end{tabular}

RNA using the PCR Gene Amplifier (EDC-810, Eastwin Life science, Inc., China). The cDNA products were amplified by PCR in a total volume of $25 \mu \mathrm{l}$ containing $0.25 \mu \mathrm{l}$ TaKaRa Ex Taq ( $5 \mathrm{U} / \mu \mathrm{l})$ and $0.5 \mu \mathrm{l}$ each of the upstream and downstream primers. Gene expressions were normalized by using $\beta$-actin as an internal standard. Experimental primers of corresponding genes are listed in Table 1.

\section{Western blot for TRPCs protein expression analysis}

The frozen left ventricular tissues were homogenized in Radio-immunoprecipitation assay (RIPA) buffer containing $1 \mathrm{mM}$ Phenylmethanesulfonyl fluoride (PMSF). The homogenates were centrifuged and the supernatants were collected. Total protein concentration was determined by Bradford assay. Protein samples $(50 \mu \mathrm{g})$ were electrophoresed and separated by $8 \%$ SDS-PAGE gel, and then transferred to Polyvinylidene difluoride (PVDF) membranes. After being blocked with $5 \%$ non-fat milk in Tris-Buffered Saline Tween-20 (TBST) for $1 \mathrm{~h}$, the membranes were incubated with specific primary antibodies overnight at $4{ }^{\circ} \mathrm{C}$. Then the membranes were incubated with horseradish peroxidase (HRP)-conjugated anti-mouse IgG or anti-rabbit IgG at a dilution of 1:10,000 in TBST for $2 \mathrm{~h}$ at room temperature. The immunoreactive bands were visualized with electrochemiluminescence (ECL) reagent and detected by DNR Bio Imaging Systems (DNR Bio-Imaging Systems Ltd, Israel). Quantification of band intensity was analyzed using Image J software. The expression levels of TRPCs were normalized to $\beta$-actin or GAPDH expression level.

\section{Statistical analysis}

Data are presented as mean \pm S.E.M. Results were analyzed using SPSS Version 13.0 software. Statistical differences were estimated with ANOVA followed by Student's t-test. A P value of less than 0.05 was considered to be statistically significant.

\section{Results}

Frequency dependence of APD of MAP in rabbit ventricular epicardium in vivo

As shown schematically in Figure 1, APD90 and APD50 shortened progressively as frequency was increased in the drug-free state. At the frequency of $4.5 \mathrm{~Hz}, 5 \mathrm{~Hz}, 5.5 \mathrm{~Hz}, 6 \mathrm{~Hz}$, $6.5 \mathrm{~Hz}, 7 \mathrm{~Hz}, 7.5 \mathrm{~Hz}$, a clear frequency dependence of APD was depicted in the MAP recording of rabbit ventricular myocardium in vivo. Myocardial APD90 from the control level (4.5 Hz) $141.53 \pm 3.85 \mathrm{~ms}$, respectively, reduced to $138.44 \pm 3.45 \mathrm{~ms}(5 \mathrm{~Hz}), 131.65 \pm 3.23 \mathrm{~ms}(5.5 \mathrm{~Hz})$, $125.94 \pm 3.11 \mathrm{~ms}(6 \mathrm{~Hz}), 119.77 \pm 3.31 \mathrm{~ms}(6.5 \mathrm{~Hz}), 112.64 \pm 1.83 \mathrm{~ms}(7 \mathrm{~Hz}), 104.69 \pm 1.58 \mathrm{~ms}$ $(7.5 \mathrm{~Hz})$. Compared with the control $(4.5 \mathrm{~Hz})$, the shortened percentages were $2.1 \pm 1.5 \%$, $6.9 \pm 1.3 \%, 10.9 \pm 1.7 \%, 15.3 \pm 1.8 \%, 20.2 \pm 2.1 \%, 25.8 \pm 2.0 \%$. 
Fig. 1. Relationship between frequency stimulation and action potential duration (APD) in ventricular epicardium in vivo. Monophasic action potentials (MAP) were recorded using a custommade contact probe, and measurements of APD at $50 \%$ and $90 \%$ repolarization were obtained at the frequency range of 4.5-7.5 Hz with an increment of $0.5 \mathrm{~Hz}$. MAP exhibited an obviously APD shortening with the increase of frequency. $\mathrm{n}=6$. $* \mathrm{P}<0.05$ vs. $4.5 \mathrm{~Hz}$ group; \# $<0.05$ vs. 5 Hz group; \&P < 0.05 vs. $5.5 \mathrm{~Hz}$ group; $+\mathrm{P}$ $<0.05$ vs. 6 Hz group; @P < 0.05 vs. 6.5 Hz group; $\% \mathrm{P}<0.05$ vs. $7 \mathrm{~Hz}$ group.

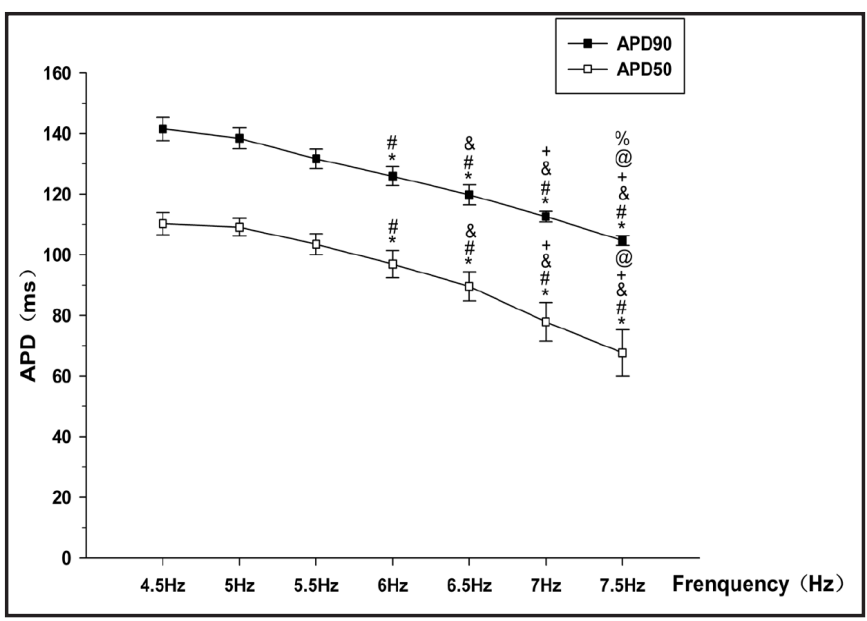

A
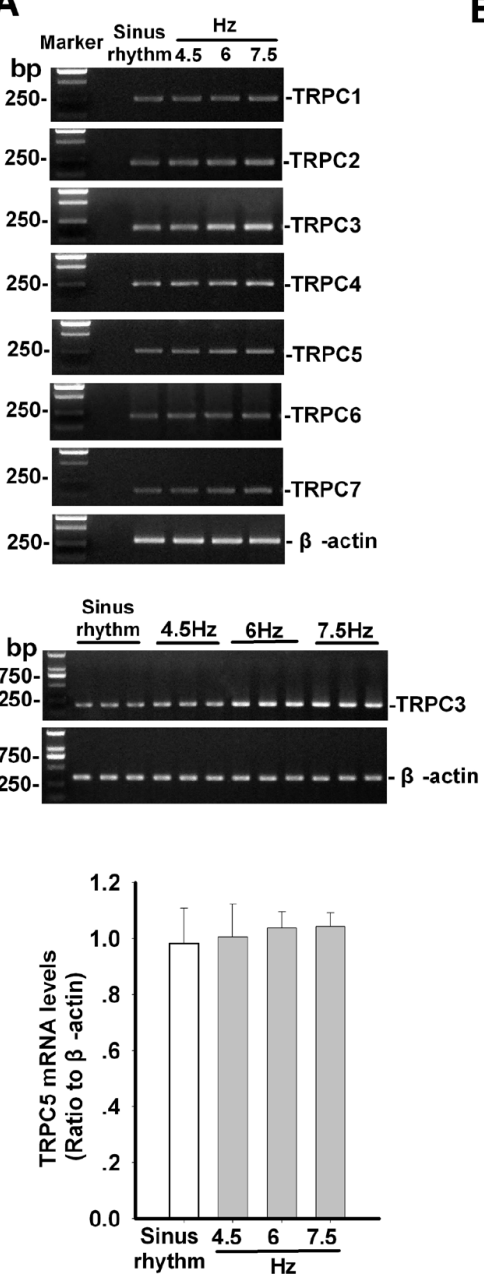

B
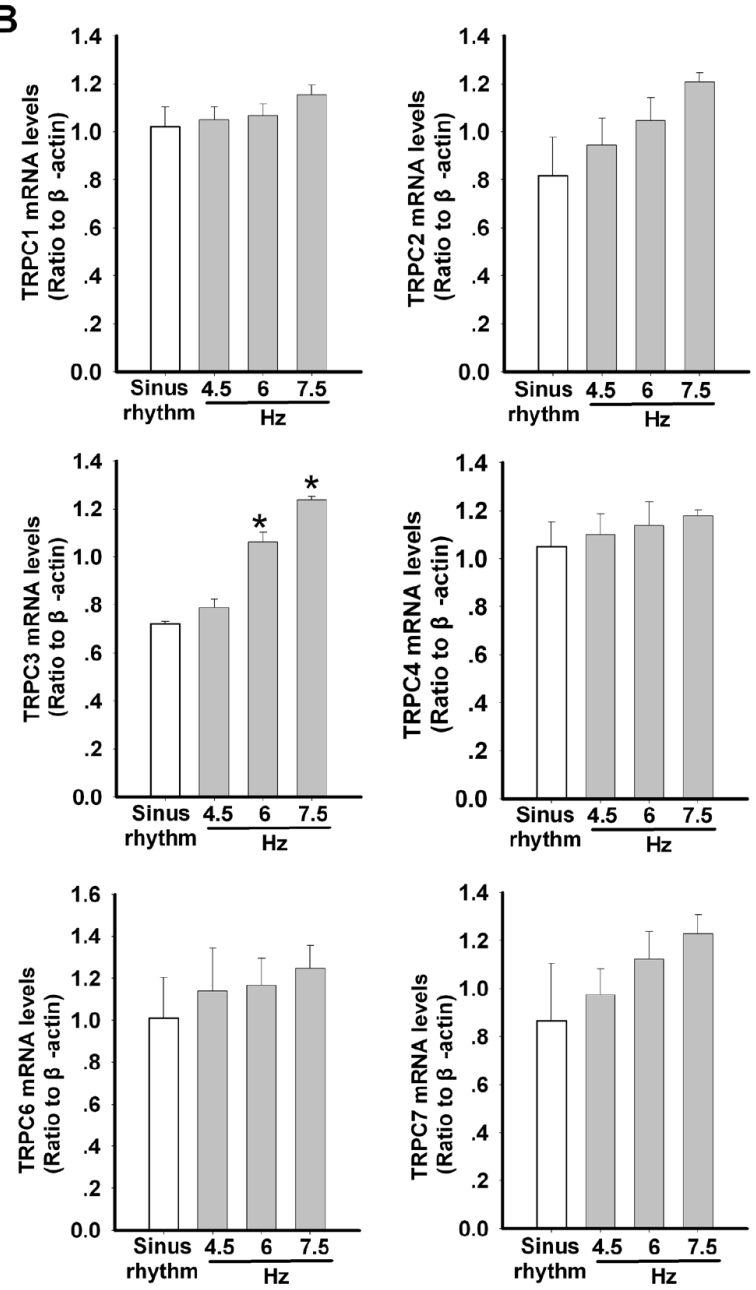

Fig. 2. Influences of different stimulation frequencies on TRPCs mRNA expression in rabbit ventricular myocardium. RT-PCR analysis of the mRNA levels of ventricular TRPC1-7 revealed that TRPC3 transcript was up-regulated with the increasing frequency. (A) Representative mRNA products for TRPCs and $\beta$-actin genes in rabbit myocardium. (B) Summarized $(n=3)$ data showing expression of TRPCs mRNA normalized to $\beta$-actin in rabbit ventricular myocardium. $* \mathrm{P}<0.05$ vs. $4.5 \mathrm{~Hz}$ group. 


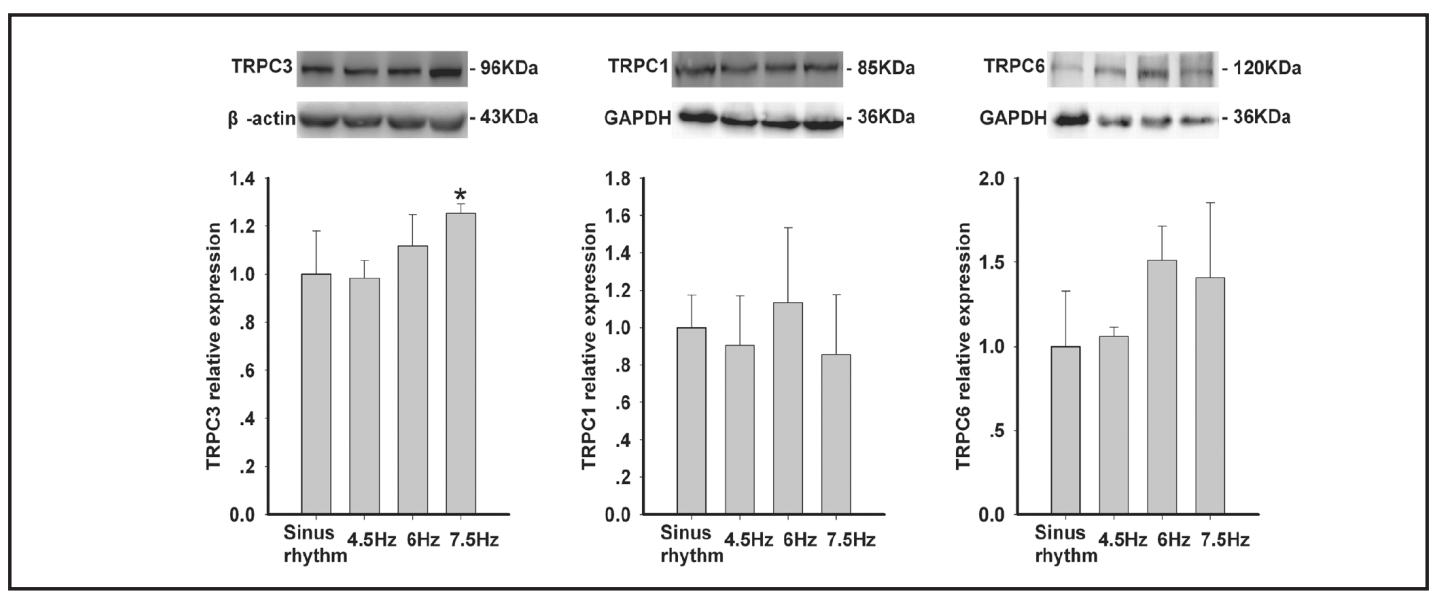

Fig. 3. Influences of different stimulation frequencies on TRPC1, 3, 6 proteins expression in rabbit ventricular myocardium. TRPC1, 3, 6 proteins were determined by Western blot and the proteins expression levels were normalized to $\beta$-actin or GAPDH. TRPC3 protein expression obviously increased in the $7.5 \mathrm{~Hz}$ group compared with $4.5 \mathrm{~Hz}$ group. $\mathrm{n}=3 \sim 5$. ${ }^{*} \mathrm{P}<0.05$ vs. $4.5 \mathrm{~Hz}$ group.

The effect of stimulation frequency on TRPCs expression in rabbit ventricular myocardium

Figure 2 demonstrated the effect of different stimulation frequencies on TRPC1-7 mRNA expression in rabbit ventricular myocardium. In the groups of $4.5 \mathrm{~Hz}, 6 \mathrm{~Hz}$ and $7.5 \mathrm{~Hz}$, TRPC3 mRNA and protein expression in rabbit ventricular myocardial were gradually raised with the increase of stimulus frequency. In contrast with control level $(4.5 \mathrm{~Hz})$, the mRNA expression of TRPC 3 remarkably grew in the $6 \mathrm{~Hz}$ and $7.5 \mathrm{~Hz}$ group $(\mathrm{P}<0.05)$, while those of myocardial TRPC1 2, TRPC4 7 showed no significant changes.

Figure 3 depicted the effect of different stimulation frequencies on TRPC1, TRPC3 and TRPC6 proteins expression. The expression of TRPC3 protein obviously increased in the 7.5 $\mathrm{Hz}$ group $(\mathrm{P}<0.05)$. The expression of TRPC1 and TRPC6 had no significant difference in the three groups.

Effect of Nef and AM on frequency dependence of APD

As shown in Figure 4, AM increased APD90 or APD50 uniformly over the entire range of steady-state frequencies studied $(4.5 \mathrm{~Hz}-6 \mathrm{~Hz})$. Compared with that before administration at the frequency of $4.5 \mathrm{~Hz}, 5 \mathrm{~Hz}, 5.5 \mathrm{~Hz}, 6 \mathrm{~Hz}, 6.5 \mathrm{~Hz}$, the prolonged percentages were respectively $11.4 \pm 4.1 \%, 10.6 \pm 3.4 \%, 6.5 \pm 1.6 \%, 7.7 \pm 1.8 \%, 8.8 \pm 3.0 \%$ after intravenous injection of AM $(5 \mathrm{mg} / \mathrm{kg}$ ) in rabbits (Fig. 4A). Thus, the action potential-prolonging effect of AM was not significantly influenced by the frequencies, in other words, it indicated the distinguishing feature of frequency independence. Nef's effect on APD resembled that of AM: Nef prolonged APD in a frequency-independent fashion (Fig. 4B). At the frequency of $4.5 \mathrm{~Hz}, 5 \mathrm{~Hz}, 5.5 \mathrm{~Hz}$, $6 \mathrm{~Hz}, 6.5 \mathrm{~Hz}, 7 \mathrm{~Hz}$, the prolonged percentages of Nef $(2.5 \mathrm{mg} / \mathrm{kg})$ injection correspondingly were $5.8 \pm 1.6 \%, 2.0 \pm 1.7 \%, 2.4 \pm 0.4 \%, 3.1 \pm 0.5 \%, 2.5 \pm 0.3 \%, 6.2 \pm 1.2 \%$ compared with that before administration (Fig. 4C).

\section{Effect of Nef and AM on TRPCs expression in rabbit ventricular myocardium}

Figure 5 demonstrated the effect of Nef or AM on TRPC1-7 mRNA expression in rabbit ventricular myocardium at the frequency of $4.5 \mathrm{~Hz}$. Nef $(2.5 \mathrm{mg} / \mathrm{kg})$ could significantly increase the expression of TRPC3 mRNA at the stimulation of $4.5 \mathrm{~Hz}$, while AM $(5 \mathrm{mg} / \mathrm{kg})$ had no such effects. Under the same stimulus conditions, the medication administration groups had no significant difference on the mRNA expression of TRPC1 2 and TRPC4 7.

Figure 6 depicted the effect of Nef or AM on TRPC1, TRPC3 and TRPC6 proteins expression at the frequency of $4.5 \mathrm{~Hz}$. In consistent with the results of mRNA expression, Nef $(2.5 \mathrm{mg} / \mathrm{kg})$ remarkably increased the expression of TRPC3 protein compared with control 
Fig. 4. Frequency independence characters of amiodarone (AM) or neferine (Nef) on APD prolongation in rabbit ventricular myocardium. (A) Effect of AM on frequency dependence of APD in rabbit ventricular myocardium. $n=5$. (B) Effect of Nef on frequency dependence of APD in rabbit ventricular myocardium. $n=4$. (C) The APD90 prolongation of AM or Nef in rabbit ventricular myocardium. $\mathrm{n}=4 \sim 5$.

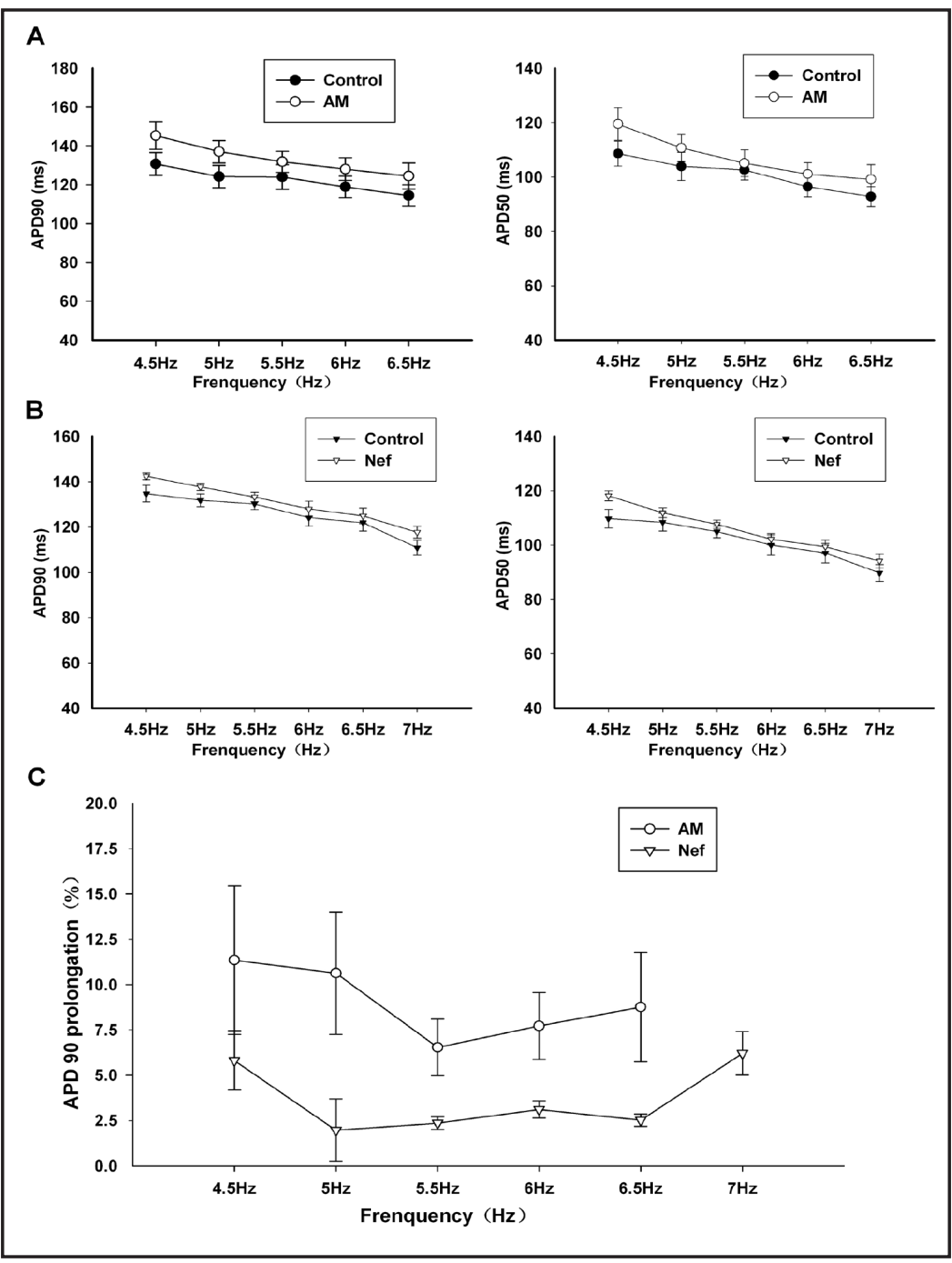

group at $4.5 \mathrm{~Hz}$, while AM (5 mg/kg) had little effect on TRPC3. Both agents did not appear to influence TRPC1 and TRPC6 expression.

\section{Discussion}

MAP recording is usually applied to reproduce the repolarization time course of transmembrane action potential (TAP) with high fidelity. In contrast to TAP, MAP can be recorded from the endocardium and epicardium of the beating heart in vivo. This MAP study has been exhibited an obviously APD shortening with the increase of frequency in rabbits ventricular epicardium in vivo. Both AM and Nef could prolongate the APD and showed characters of rate independence at the designed frequencies. In the groups of $4.5 \mathrm{~Hz}, 6 \mathrm{~Hz}$ and $7.5 \mathrm{~Hz}$, TRPC3 mRNA and protein expression in rabbit ventricular myocardium were gradually raised with the increase of stimulus frequency. Nef $(2.5 \mathrm{mg} / \mathrm{kg})$ could significantly increase the expression of TRPC 3 at the stimulation of $4.5 \mathrm{~Hz}$.

It has been demonstrated that faster stimulation rates lead to a physiological shortening of APD, a phenomenon named frequency dependence of APD in some mammal species. APD changes are proved to be directly determined by the relation of inward or outward current, i.e, the net membrane current (Inet). Several hypotheses have been developed so far to explain the mechanism of frequency dependence of APD. In general, a net outward 


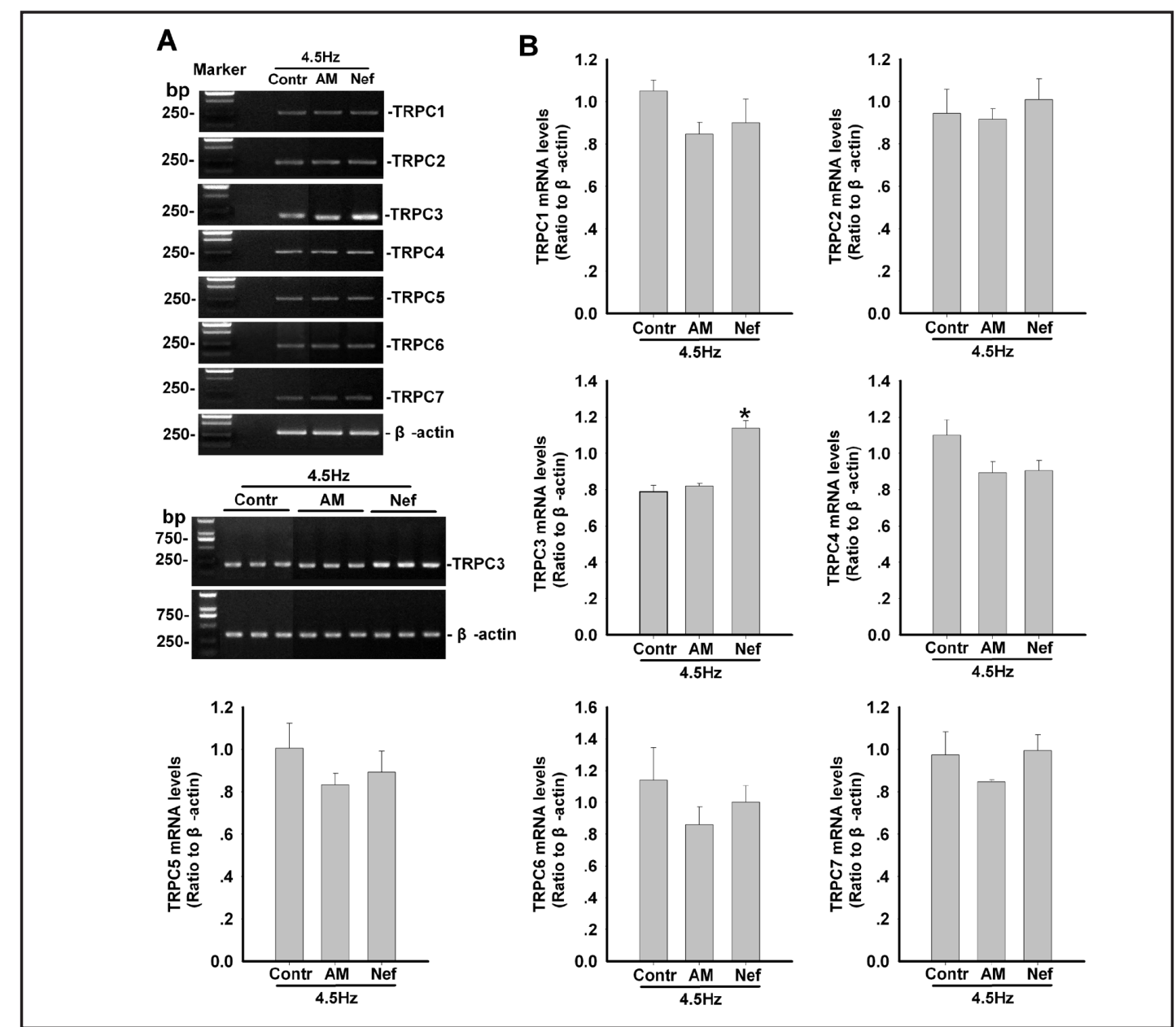

Fig. 5. Influences of neferine (Nef) or amiodarone (AM) on TRPCs mRNA expression in rabbit ventricular myocardium at the frequency of 4.5 Hz. RT-PCR analysis of the mRNA levels of ventricular TRPC1-7 showed that Nef $(2.5 \mathrm{mg} / \mathrm{kg})$ could significantly increase TRPC3 transcript at the stimulation of $4.5 \mathrm{~Hz}$. (A) Representative mRNA products for TRPCs and $\beta$-actin genes in rabbit ventricular myocardium. (B) Summarized $(\mathrm{n}=3)$ data showing expression of TRPCs mRNA normalized to $\beta$-actin in rabbit ventricular myocardium. ${ }^{*} \mathrm{P}$ $<0.05$ vs. control $4.5 \mathrm{~Hz}$ group.

current can eventually lead to the shortening of APD when the stimulus frequency increased. The cardiac action potential is formed by various ionic currents and the generation of net outward currents through increasing frequency may be caused by decreases of the inward calcium current, increases of the outward potassium current, or the NCX current, et al.

The change of the cardiac APD with the stimulation rate can cause transmembrane movement of various ions which can also lead to alterations of intracellular ionic concentration. In this process, electrical remodeling or structural remodeling of cardiac repolarization has been gradually formed, which is one of the critical mechanisms in the developments of atrial fibrillation (AF) or congestive heart failure (CHF) [19]. Xiao et al., based on experimental results that rapid cardiomyocyte firing decreases transient outward potassium current (Ito) density, suggested that the rate-dependent Ito downregulation is mediated by increased $\mathrm{Ca}^{2+} /$ calmodulin-activated $\mathrm{Ca}^{2+} /$ calmodulin-dependent protein kinase II (CaMKII) and calcineurin/Nuclear factor of activated T-cells (NFAT) signaling in canine cardiomyocytes [20]. Bosch et al. demonstrated that L-type calcium current and Ito are reduced in early phases of electrical remodeling in rabbit atrium [21]. It has been 


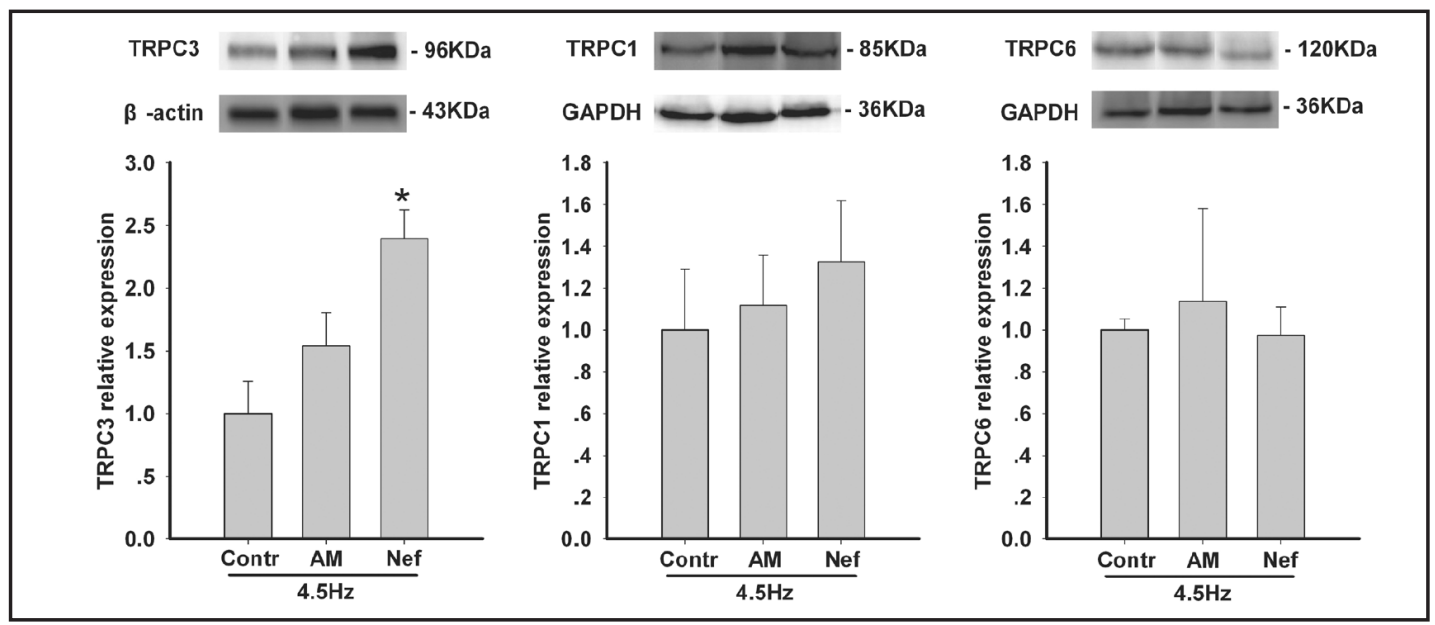

Fig. 6. Effect of neferine (Nef) or amiodarone (AM) on TRPC1, 3, 6 proteins expression in rabbit ventricular myocardium at the frequency of $4.5 \mathrm{~Hz}$. TRPC1, 3, 6 proteins were determined by Western blot, and the proteins expression levels were normalized to $\beta$-actin or GAPDH. Nef $(2.5 \mathrm{mg} / \mathrm{kg})$ significantly increased TRPC3 protein expression compared with control group at $4.5 \mathrm{~Hz} . \mathrm{n}=3 \sim 5$. ${ }^{*} \mathrm{P}<0.05$ vs. control $4.5 \mathrm{~Hz}$ group.

tested that reduced $\mathrm{I}_{\mathrm{Ca}, \mathrm{L}}$ in patients with $\mathrm{AF}$ is associated with increased protein phosphatase activity [22]. Therefore, electrical remodeling or structural remodeling caused by abnormal rate is an important factor of proarrhythmia. A recent report by Harada, M., et al. described that TRPC3 channel expression increased in AF dogs by causing NFAT-mediated downregulation of microRNA-26 and resulted in TRPC3-dependent enhancement of fibroblast proliferation and differentiation [23].

In the present work, we observed that the expression of TRPC3 increased along with stimulus frequency. To investigate its reason, the increased expression of TRPC3 may be caused by elevation of intracellular calcium concentration through opening of L-type $\mathrm{Ca}^{2+}$ channels under high-frequency stimulation [24]. Then $\mathrm{Ca}^{2+} / \mathrm{CaM}$ activates calcineurin (CaN), which induces dephosphorylation of NFAT in the cytoplasm and permits its translocation to the nucleus where it participates in the gene expression and transcription of TRPC3 [25]. In another hand, $\mathrm{Ca}^{2+} / \mathrm{CaM}$ can also indirectly activate $\mathrm{CaN} / \mathrm{NFAT}$ pathway through CaMKII, resulting in the increased expression of TRPC3 [20].

Many class III antiarrhythmic agents that prolong the APD through selective IKr blocking, such as dofetilide, d-sotalol, reduce their effectiveness at fast heart rates due to reverse frequency dependence [26]. Conversely, these drugs induce maximum prolongation of APD at slow fast rates and can more easily lead to torsade de pointes (Tdp). Thus, drugs exhibiting reverse use dependence may even render their proarrhythmic effects. This limits their efficacy for controlling arrhythmias. AM is usually classified as a class III antiarrhythmic agent for acting primarily by prolonging the APD through blocking cardiac potassium channels. But it also has been exhibited the effects of blocking sodium and calcium channels [27]. The frequency-dependent effects of AM on repolarization may differ from those of other class III antiarrhythmic agents. In our study, AM-induced prolongation of the APD90 occurred at a range of $4.5 \sim 7 \mathrm{~Hz}$ without significant attenuation during rapid pacing and displayed a characteristic of rate independence, consisting with previous in vitro and in vivo studies of AM [28, 29]. The advantage of AM with less reverse frequency dependence over other class III antiarrhythmic drugs maybe lie in its blocking effects on multiple ion channel.

Nef is one of the bisbenzylisoquinoline alkaloids extracted from the seed embryo of Nelumbo nucifera Gaertn. It has been demonstrated that Nef could show antiarrhythmic effects and inhibit myocardial contraction force [17]. Its mechanisms may be associated with non-specific inhibition of the current of $\mathrm{Ca}^{2+}, \mathrm{Na}^{+}$and $\mathrm{K}^{+}$.

In the present study, we observed that Nef cloud also exhibit rate-independent effect on the prolongation of APD which is similar to AM. Nef could significantly increase the 
expression of TRPC3 mRNA and protein at the stimulation of $4.5 \mathrm{~Hz}$ while AM had no such effects. We speculate that the effects of increasing TRPC3 expression of Nef are related to APD extension. Nef may promote calcium influx through increasing TRPC3 expression so as to lengthen APD.

This study observed that frequency-dependent shortening of APD could promote TRPC3 expression in rabbit ventricular myocardial. Nef might lengthen APD through increasing TRPC3 expression. We presumed that the increasing intracellular calcium during rapid pacing could activate CaN/NFAT pathway so as to promote the transcription and expression of TRPC3. Further studies are needed to determine how frequency-dependent shortening of APD promotes TRPC3 expression.

In summary, our findings demonstrated that rate-dependent shortening of APD at the range of 4.5-7.5 Hz was associated with the growing expression of TRPC3. AM and Nef displayed the rate-independent prolongation of APD. Nef may lengthen APD via increasing the expression of TRPC3.

\section{Conflict of Interest}

The authors are in agreement with the content of this manuscript. All authors declare no conflicts of interest.

\section{Acknowledgements}

This work was supported by the 43th Scientific Research Foundation for the Returned Overseas Chinese Scholars, Ministry of Education of China and the Central Authorities of an Institution of Higher Learning of Scientific Research Special Fund of China (2011TS071).

\section{References}

1 Dorian P, Newman D: Rate dependence of the effect of antiarrhythmic drugs delaying cardiac repolarization: an overview. Europace 2000;2:277-285.

2 Boyett MR, Fedida D: Changes in the electrical activity of dog cardiac purkinje fibres at high heart rates. J Physiol 1984;350:361-391.

- 3 Stengl M, Volders PG, Thomsen MB, Spatjens RL, Sipido KR, Vos MA: Accumulation of slowly activating delayed rectifier potassium current (iks) in canine ventricular myocytes. J Physiol 2003;551:777-786.

4 Janvier NC, Boyett MR: The role of na-ca exchange current in the cardiac action potential. Cardiovasc Res 1996;32:69-84.

-5 Spencer CI, Sham JS: Effects of $\mathrm{Na}^{+} / \mathrm{Ca}^{2+}$ exchange induced by sr $\mathrm{Ca}^{2+}$ release on action potentials and afterdepolarizations in guinea pig ventricular myocytes. Am J Physiol Heart Circ Physiol 2003;285:H2552-H2562.

-6 Williams BA, Dickenson DR, Beatch GN: Kinetics of rate-dependent shortening of action potential duration in guinea-pig ventricle; Effects of ik1 and ikr blockade. Br J Pharmacol 1999;126:1426-1436.

-7 Li GR, Nattel S: Properties of human atrial ica at physiological temperatures and relevance to action potential. Am J Physiol 1997;272:H227-H235.

8 Moran MM, McAlexander MA, Biro T, Szallasi A: Transient receptor potential channels as therapeutic targets. Nat Rev Drug Discov 2011;10:601-620.

-9 Albert AP: Gating mechanisms of canonical transient receptor potential channel proteins: role of phosphoinositols and diacylglycerol. Adv Exp Med Biol 2011;704:391-411.

10 Nilius B, Owsianik G: The transient receptor potential family of ion channels. Genome Biol 2011;12:218. 
11 Sabourin J, Robin E, Raddatz E: A key role of trpc channels in the regulation of electromechanical activity of the developing heart. Cardiovasc Res 2011;92:226-236.

12 Ward ML, Williams IA, Chu Y, Cooper PJ, Ju YK, Allen DG: Stretch-activated channels in the heart: contributions to length-dependence and to cardiomyopathy. Prog Biophys Mol Biol 2008;97:232-249.

13 von Lewinski D, Kockskamper J, Pieske B: Stretch-induced slow force response in mammalian ventricular myocardium; in Kamkin A, Kiseleva I (eds): Source Mechanosensitivity in Cells and Tissues. Moscow, Academia, 2005.

14 Lerman BB, Engelstein ED, Burkhoff D: Mechanoelectrical feedback: role of beta-adrenergic receptor activation in mediating load-dependent shortening of ventricular action potential and refractoriness. Circulation 2001;104:486-490.

15 Tsujimae K, Suzuki S, Murakami S, Kurachi Y: Frequency-dependent effects of various ikr blockers on cardiac action potential duration in a human atrial model. Am J Physiol Heart Circ Physiol 2007;293:H660-H669.

16 Hondeghem LM, Snyders DJ: Class iii antiarrhythmic agents have a lot of potential but a long way to go. Reduced effectiveness and dangers of reverse use dependence. Circulation 1990;81:686-690.

17 Qian JQ: Cardiovascular pharmacological effects of bisbenzylisoquinoline alkaloid derivatives. Acta Pharmacol Sin 2002;23:1086-1092.

18 Dong ZX, Zhao X, Gu DF, Shi YQ, Zhang J, Hu XX, Hu MQ Yang BF, Li BX: Comparative effects of liensinine and neferine on the human ether-a-go-go-related gene potassium channel and pharmacological activity analysis. Cell Physiol Biochem 2012;29:431-442.

19 Michael G, Xiao L, Qi XY, Dobrev D, Nattel S: Remodelling of cardiac repolarization: how homeostatic responses can lead to arrhythmogenesis. Cardiovasc Res 2009;81:491-499.

20 Xiao L, Coutu P, Villeneuve LR, Tadevosyan A, Maguy A, Le Bouter S, Allen BG, Nattel S: Mechanisms underlying rate-dependent remodeling of transient outward potassium current in canine ventricular myocytes. Circ Res 2008;103:733-742.

-21 Bosch RF, Scherer CR, Rub N, Wohrl S, Steinmeyer K, Haase H, Busch AE, Seipel L, Kuhlkamp V: Molecular mechanisms of early electrical remodeling: transcriptional downregulation of ion channel subunits reduces i(ca,l) and i(to) in rapid atrial pacing in rabbits. J Am Coll Cardiol 2003;41:858-869.

22 Christ T, Boknik P, Wohrl S, Wettwer E, Graf EM, Bosch RF, Knaut M, Schmitz W, Ravens U, Dobrev D: L-type $\mathrm{Ca}^{2+}$ current downregulation in chronic human atrial fibrillation is associated with increased activity of protein phosphatases. Circulation 2004;110:2651-2657.

-23 Harada M, Luo X, Qi XY, Tadevosyan A, Maguy A, Ordog B, Ledoux J, Kato T, Naud P, Voigt N, Shi Y, Kamiya K, Murohara T, Kodama I, Tardif JC, Schotten U, Van Wagoner DR, Dobrev D, Nattel S: Transient receptor potential canonical-3 channel-dependent fibroblast regulation in atrial fibrillation. Circulation 2012;126:2051-2064.

24 Carmeliet E: Intracellular $\mathrm{Ca}^{2+}$ concentration and rate adaptation of the cardiac action potential. Cell Calcium 2004;35:557-573.

25 Dominguez-Rodriguez A, Ruiz-Hurtado G, Benitah JP, Gomez AM: The other side of cardiac $\mathrm{Ca}^{2+}$ signaling: transcriptional control. Front Physiol 2012;3:452.

-26 Baskin EP, Lynch JJ: Comparative effects of increased extracellular potassium and pacing frequency on the class iii activities of methanesulfonanilide ikr blockers dofetilide, d-sotalol, e-4031, and mk-499. J Cardiovasc Pharmacol 1994;24:199-208.

27 Kodama I, Kamiya K, Toyama J: Cellular electropharmacology of amiodarone. Cardiovasc Res 1997;35:1329.

28 Sager PT, Uppal P, Follmer C, Antimisiaris M, Pruitt C, Singh BN: Frequency-dependent electrophysiologic effects of amiodarone in humans. Circulation 1993;88:1063-1071.

29 Kodama I, Suzuki R, Kamiya K, Iwata H, Toyama J: Effects of long-term oral administration of amiodarone on the electromechanical performance of rabbit ventricular muscle. Br J Pharmacol 1992;107:502-509. 